\title{
ON THE STATUS OF LEPTOTHORAX MAYR AND SOME OF ITS SUBGENERA
}

\author{
By Marion R. Smith \\ Bureau of Entomology and Plant Quarantine, Agricultural \\ Research Administration, United States Department \\ of Agriculture
}

'The genus Leptothorax was established by Mayr in $\mathbf{1 8 5 5}$ (Verh. Zool.-Bot. Gesell. Wien 5:431) for a number of Palearctic ants, such as clypeatus (Mayr), acervorum (F.), muscorum (Nyl.), tuberum (F.), and unifasciatus (Latr.), without genotype designation. 'This was not done until 1903, when Bingham (Fauna of British India (Hymenoptera), vol. 2, p. 214) selected acervorum as the genotype. Ruzsky, in 1904 (Zapiski Imp. Russk. Geogr. Obshch. 41 (1) : 288), described a new genus, Mychothorax, and chose the same form, acervorum, as a genotype, thus making Mychothorax an isogenotypic synonym of Leptothorax. W. M. Wheeler, in 1911 (Ann. N. Y. Acad. Sci. 21:166), overlooking Bingham's previous designation of acervorum as genotype of Leptothorax, named acervorum a second time as type of this genus. Then in 1922, Emery (in Wytsman's, Genera Insectorum, fascicule 174 c:248), apparently unaware of the previous designation, selected clypeatus as genotype for Leptothorax, presumably because it was the first species listed by Mayr in his original article; and this concept has been universally adopted. However, since Bingham's is the first valid genotype designation for Leptothorax, the genus must be based on acervorum.

It thus becomes necessary to propose a new subgenus for Emery's concept of Leptothorax, subg. Leptothorax. This group, which is both Holarctic and Neotropical in distribution, and contains a large number of North American ants, I propose to name Myrafant, for my wife, whose maiden name was Myra Fant. 
Leptothorax, subg. Myrafant, new subgenus tion.

Type: Leptothorax curvispinosus Mayr. By present designa-

This subgenus includes such common North American forms as fortinodis Mayr, rugatulus Emery, longispinosus Roger, texanus W. M. Wheeler, tricarinatus Emery and many others. For a list of forms see Emery, 1922 (in Wytsman's, Genera Insectorum, fascicule 174 c:251-259).

The worker has 11- or 12-segmented antennae; thoracic humeri usually rounded, occasionally subangular; mesoepinotal impression on the dorsal surface of the thorax usually absent, if present, scarcely perceptible.

In the preparation of a catalogue of Nearctic ants, it was noted that Goniothorax Emery, 1896, is preoccupied by Goniothorax Milne-Edwards, 1879. As Nesomyrmex W. M. Wheeler is the next available name, it supplants Goniothorax Emery. The synonymy is as follows:

Leptothorax subg. Nesomyrmex W. M. Wheeler

Leptothorax, subgenus Goniothorax Emery, 1896, Bol. Soc. Ent. Ital. $28: 26,58$. Preoccupied. Type: Leptothorax vicinus Mayr. Designated by W. M. Wheeler, 1911.

Nesomyrmex W. M. Wheeler, 1910, Bul. Amer. Mus. Nat. Hist. $28: 259$. Type: Nesomyrmex clavipilis W. M. Wheeler. Monobasic.

Caulomyrma Forel, 1914, Bul. Soc. Vaud. des Sci. Nat. 50: 233. Type: Leptothorax echinatinodis Forel. Original designation.

Most of the ants of this subgenus occur in the Ethiopian, Oriental and Neotropical Regions. Our only known North American species is wilda M. R. Smith, from extreme southern Texas. 

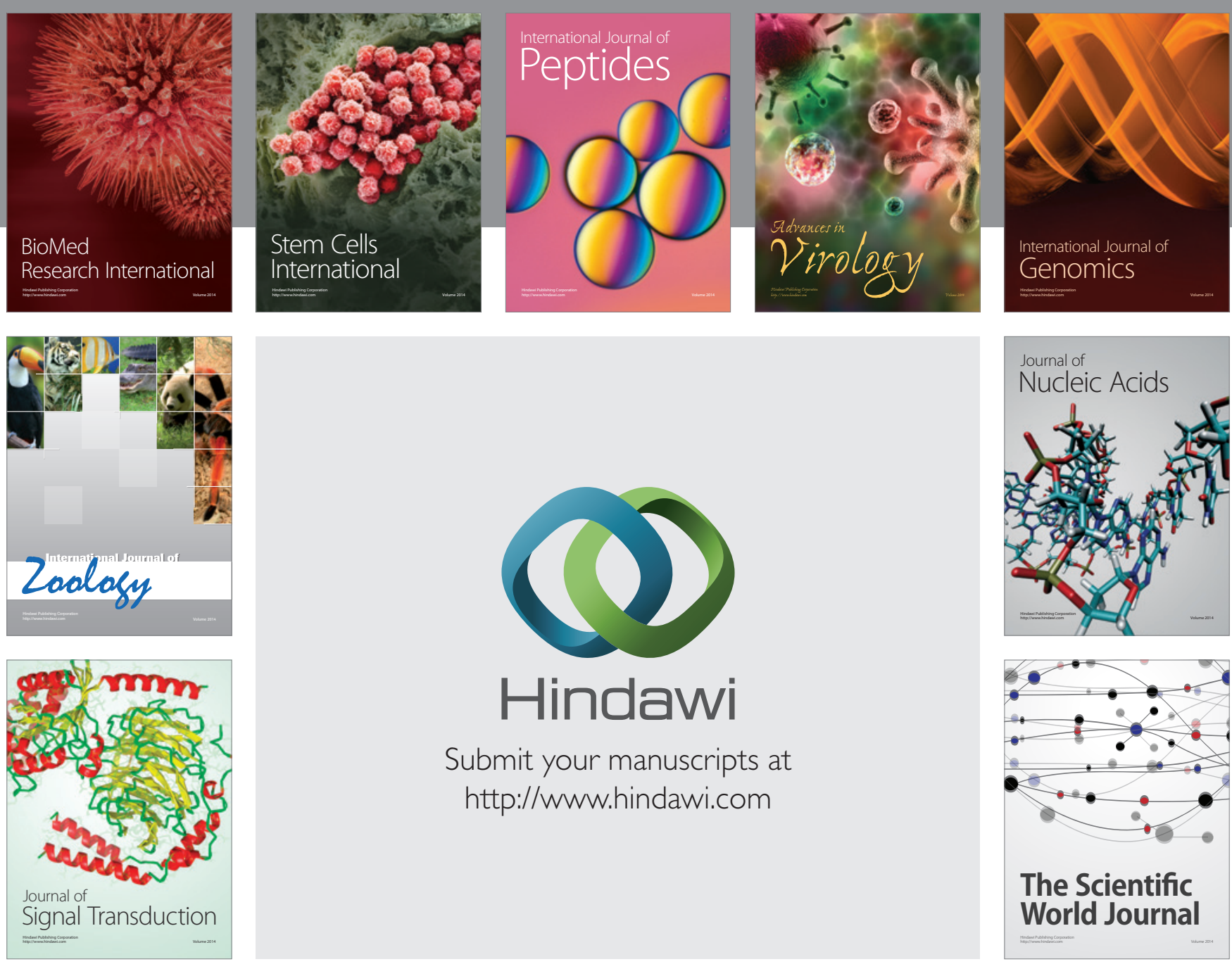

Submit your manuscripts at

http://www.hindawi.com
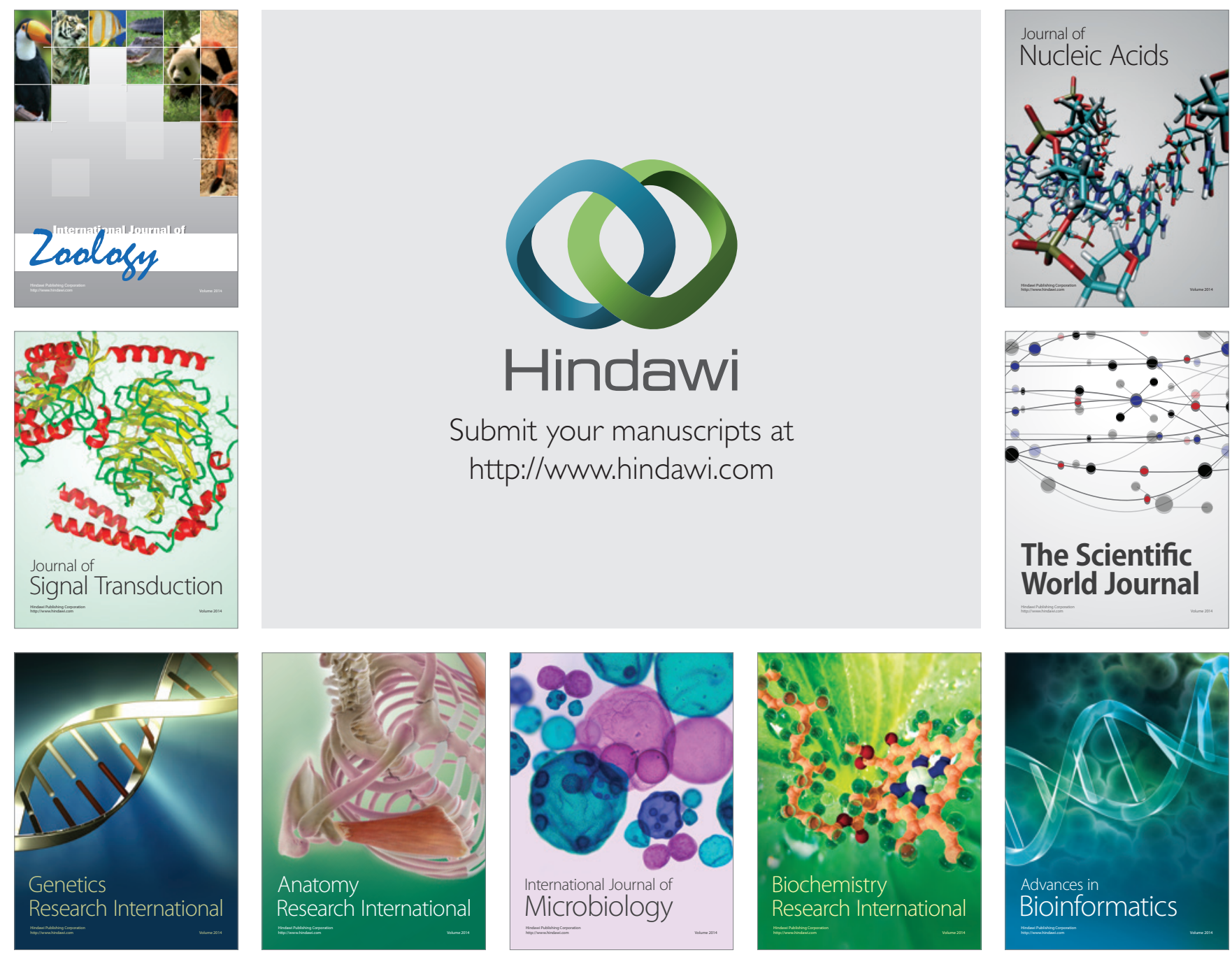

The Scientific World Journal
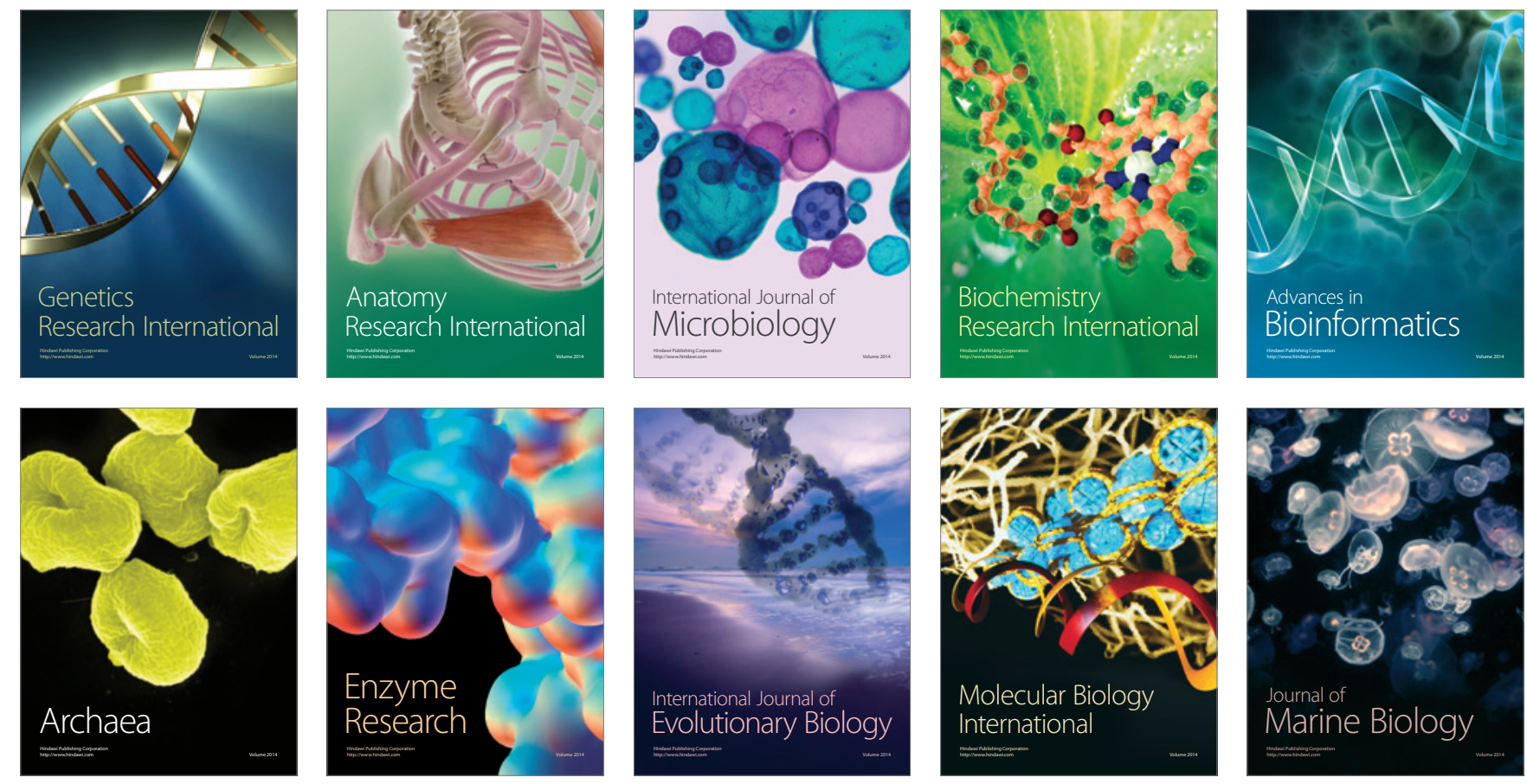